\title{
In Vitro Antiproliferative and Antioxidant Effects of Extracts from Rubus caesius Leaves and Their Quality Evaluation
}

\author{
Daniel Mirosław Grochowski, ${ }^{1}$ Roman Paduch, ${ }^{2,3}$ Adrian Wiater, ${ }^{4}$ \\ Adrianna Dudek, ${ }^{2}$ Małgorzata Pleszczyńska, ${ }^{4}$ Monika Tomczykowa, ${ }^{5}$ \\ Sebastian Granica, ${ }^{6}$ Paulina Polak, ${ }^{4}$ and Michał Tomczyk ${ }^{1}$ \\ ${ }^{1}$ Department of Pharmacognosy, Medical University of Białystok, ul. Mickiewicza 2a, 15-230 Białystok, Poland \\ ${ }^{2}$ Department of Virology and Immunology, Maria Curie-Skłodowska University, ul. Akademicka 19, 20-033 Lublin, Poland \\ ${ }^{3}$ Department of General Ophthalmology, Medical University of Lublin, ul. Chmielna 1, 20-079 Lublin, Poland \\ ${ }^{4}$ Department of Industrial Microbiology, Maria Curie-Skłodowska University, ul. Akademicka 19, 20-033 Lublin, Poland \\ ${ }^{5}$ Department of Organic Chemistry, Medical University of Białystok, ul. Mickiewicza 2a, 15-222 Białystok, Poland \\ ${ }^{6}$ Department of Pharmacognosy and Molecular Basis of Phytotherapy, Medical University of Warsaw, ul. Banacha 1, \\ 02-097 Warsaw, Poland
}

Correspondence should be addressed to Michał Tomczyk; michal.tomczyk@umb.edu.pl

Received 18 July 2016; Accepted 6 December 2016

Academic Editor: Dolores García Giménez

Copyright (C) 2016 Daniel Mirosław Grochowski et al. This is an open access article distributed under the Creative Commons Attribution License, which permits unrestricted use, distribution, and reproduction in any medium, provided the original work is properly cited.

\begin{abstract}
The present study was performed to evaluate the effect of different extracts and subfractions from Rubus caesius leaves on two human colon cancer cell lines obtained from two stages of the disease progression lines HT29 and SW948. Tested samples inhibited the viability of cells, both HT29 and SW948 lines, in a concentration-dependent manner. The most active was the ethyl acetate fraction which, applied at the highest concentration $(250 \mu \mathrm{g} / \mathrm{mL})$, decreased the viability of cells (HT29 and SW948) below 66\%. The extracts and subfractions were also investigated for antioxidant activities on DPPH and FRAP assays. All extracts, with the exception of water extract at a dose of $250 \mu \mathrm{g} / \mathrm{mL}$, almost totally reduced DPPH. The highest $\mathrm{Fe}^{3+}$ ion reduction was shown for the diethyl and ethyl acetate fractions. It was more than 6.5 times higher (at a dose $250 \mu \mathrm{g} / \mathrm{mL}$ ) as compared to the control. The LC-MS studies of the analysed preparations showed that all samples contain a wide variety of polyphenolics, among which ellagitannins turned out to be the main constituents with dominant ellagic acid, sanguiin $\mathrm{H}-6$, and flavonol derivatives.
\end{abstract}

\section{Introduction}

Drugs of natural origin have been used throughout history to cure or prevent diseases. Modern phytotherapy is engaged in the production of remedies from materials derived from plants and their use in effective and safe therapy. Their main action could be aimed at three aspects: cytostatic activity, especially when therapy concerns tumour tissue, and antiinflammatory and antioxidative or free radical reduction actions. With all this in mind, we have tried to evaluate the cytotoxic and antioxidant activities of Rubus caesius extracts on two human colon cancer cell lines obtained from two stages of disease progression. Additionally, the full phytochemical profile of all the investigated extracts obtained from $R$. caesius leaves based on the HPLC-DAD-MS ${ }^{n}$ method has been characterized for the first time. $R$ caesius is a wellknown shrub (dewberry) extending from Europe to Siberia, but it can also be found in the United States. Folk medicine attributes many virtues to $R$. caesius. Further studies are required to confirm the pharmacological relevance of the findings, but now there are great expectations for its wide therapeutic application [1].

\section{Materials and Methods}

2.1. Plant Material and Preparation of Extracts and Their Fractions. The leaves from wild species of $R$. caesius were collected during June-July 2012-2014 from Puszcza Knyszyńska, 
near Bialystok, Poland. A voucher specimen of plant RC11027 has been deposited in the Herbarium of the Department of Pharmacognosy, Medical University of Białystok, Poland. All plant samples, extracts, and fractions were prepared according to previously described methods [2]. Yields are as follows: RC1, $83 \mathrm{mg}$; RC2, $79 \mathrm{mg}$; RC3, $101 \mathrm{mg}$; RC4, $9 \mathrm{mg}$; RC5, $28 \mathrm{mg}$; RC6, $96 \mathrm{mg}$.

2.2. HPLC-DAD-MS ${ }^{3}$ Analysis. The HPLC-DAD-MS ${ }^{3}$ analysis was performed using similar conditions described previously [2]. HPLC analyses of samples were carried out on a reversed-phase Kinetex XB-C18, $100 \mathrm{~mm} \times 2.1 \mathrm{~mm} \times 1.7 \mu \mathrm{m}$ column (PHENOMENEX, USA). Compounds were analysed in negative and positive ion modes (the $\mathrm{MS}^{2} 152,-162$, and $-176 \mathrm{amu}$ ). In the case of the detection of one of the neutral loss masses $\mathrm{MS}^{3}$ fragmentation was performed. Analysis was carried out using scan from $m / z 70$ to 2.200 .

2.3. Cell Cultures. Two human colon tumour cell lines were used. HT29 (ATCC ${ }^{\circledR}$ HTB-38 $^{\text {TM }}$ ) and SW948 (ATCC CCL-237 ${ }^{\mathrm{TM}}$ ) cell lines representing early and late stages of tumour development were cultured as monolayers in $25 \mathrm{~mL}$ culture flasks (NUNC, Rochester, USA). All cell lines were maintained in RPMI 1640 medium supplemented with 10\% FBS (foetal bovine serum) (v/v) and antibiotics $(100 \mathrm{U} / \mathrm{mL}$ penicillin, $100 \mu \mathrm{g} / \mathrm{mL}$ streptomycin) (SIGMA, St. Louis, MO, USA) at $37^{\circ} \mathrm{C}$ in a humidified atmosphere with $5 \% \mathrm{CO}_{2}$.

2.4. MTT Assay. The MTT assay is based on the conversion of a yellow tetrazolium salt by viable cells to purple crystals of formazan. The reaction is catalysed by mitochondrial succinyl dehydrogenase. Cell sensitivity to $R$. caesius extracts was analysed in a spectrophotometric 3-(4,5-dimethylthiazol-2yl)-2,5-diphenyltetrazolium bromide (MTT) test according to Mosmann [3].

2.5. Neutral Red (NR) Uptake Assay. The NR cytotoxicity assay is based on the uptake and lysosomal accumulation of the supravital dye, Neutral Red. Dead or damaged cells do not take up the dye. The method was used as described earlier [4].

2.6. Nitric Oxide (NO) Measurement. Nitrate, a stable end product of NO, was determined in culture supernatants by a spectrophotometric method based on the Griess reaction. The course of the procedure has been described previously [5].

2.7. $\mathrm{DPPH}^{\circ}$ Free Radical Scavenging Test. The free radical scavenging activity of extracts was analysed by the 1,1diphenyl-2-picrylhydrazyl (DPPH) assay. The test is based on the ability of antioxidants to reduce the stable dark violet radical $\mathrm{DPPH}^{\bullet}$ (SIGMA, USA) to the yellow diphenylpicrylhydrazine. The methodology has been described in our previous study [5].

2.8. Ferric-Reducing Antioxidant Power (FRAP) Assay. The FRAP method was used to determine the antioxidative capacity of the tested extracts. The procedure has been described earlier [4].
2.9. Statistical Analysis. The biological experiments were repeated three times. The data were analysed using one-way ANOVA followed by Dunnett's multiple comparison post hoc test. Only results with significance of $p \leq 0.05$ were considered significant.

\section{Results and Discussion}

Many species classified to the genus Rubus have been recognized as potential agents with significant effects on human health [6-10]. In the present work we selected leaves of blackberry $R$. caesius (dewberry) species traditionally used as a remedy to treat many diseases, among them gastrointestinal bleeding and diarrhoea [1, 11]. More recently, Dudzińska and coauthors indicated that the extracts obtained from dewberry leaves demonstrate antiplatelet activities in whole blood, where neutrophils play a pivotal role in mediating their effects on platelets. Although these extracts do not hamper the neutrophil oxidative metabolism and do not influence the expression of neutrophil adhesive receptors, they demonstrate an ability to lower the reactive oxygen level produced by neutrophils [12]. According to the reviewed literature, little is known about the potential antiproliferative and antioxidant activity of dewberry's leaves which encouraged us to investigate this plant growing in Poland. In addition, there is no solid evidence describing the chemical composition of the species.

For the first time, we initiated a detailed phytochemical analysis of secondary metabolites and confirmed the presence of derivatives of quercetin and kaempferol, as well as ellagitannins $[1,11]$. The fingerprints of the analysed $R$. caesius extracts were established using the HPLC-DAD-MS ${ }^{3}$ method. The analysis revealed the presence of thirty-five constituents (Figure 1) comprising ellagitannins and their derivatives, phenolic acids, as well as flavonoids. In the RC1 (water), RC2 (50\% methanol), and RC3 (methanol) extracts ellagic acid [22] and sanguiin H-6 [23] were detected as the dominating constituents. The subfractions RC4 (diethyl ether), RC5 (ethyl acetate), and RC6 ( $n$-butanol) contained a wide variety of phenolic acids $[2,5,9,11,12,16,22,31$ and 32], flavonoids, mainly, quercetin [18, 19, 26 and 34], and kaempferol $[25,27,30,33$ and 35] derivatives, as well as ellagitannins and related compounds $[4,6-8,14$ and 29]. Table 1 contains detailed UV-Vis and MS data for all the detected compounds together with their preliminary or full identification. These phytoconstituents express reductive activity on free radicals and may limit the appearance of mutations or even participate in DNA repair [24]. There are a few reports concerning the antitumour activity of other Rubus leaves extracts, but no data are available supporting the extracts from dewberry leaves $[15,16,22,25,26]$. Previous studies on in vitro models suggest that berry from Rubus species may influence colorectal cancer cell survival in concert terms proliferation and apoptosis [17]. Komes and coworkers also revealed that infusion from $R$. fruticosus leaves may induce cytotoxic action against human colon cells, depending of time and concentration [26]. On the other hand, cancer development is closely associated with inflammation and mutatory microenvironments containing 


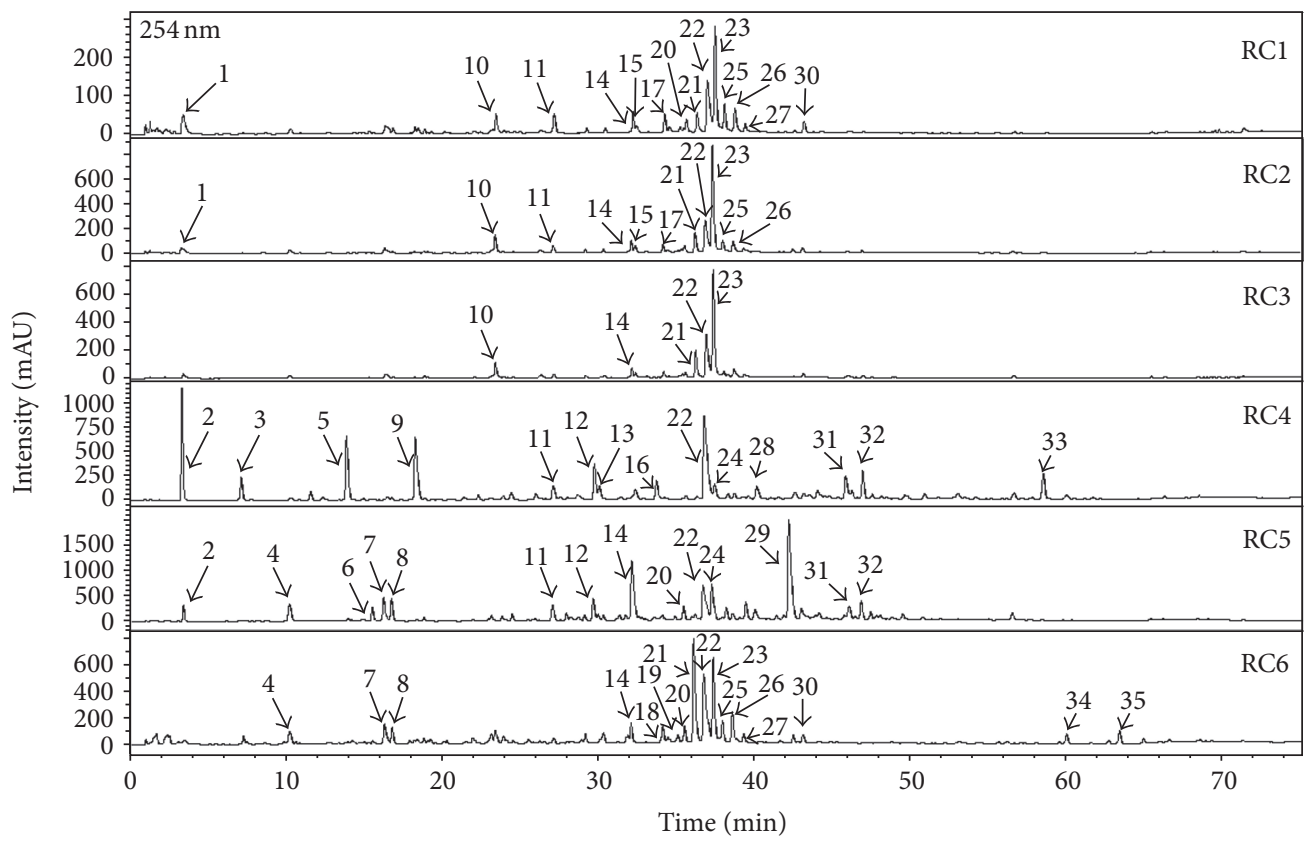

FIGURE 1: UHPLC chromatograms of $R$. caesius samples (RC1-RC6) recorded at $254 \mathrm{~nm}$.

free radicals. In another study, a triterpenoid-rich fraction from $R$. coreanus has been shown to express strong antiinflammatory activity towards injured colonic tissue [27].

Therefore, we decided to aim our study at the cytotoxic and reduction activity of $R$. caesius leaves in human colon carcinoma cells. Studies on the biological activity of different extracts and subfractions obtained from dewberry were based on two analyses (MTT and NR assays) which were performed on two human colon tumour cell lines HT29 (Duke's A) and SW948 (Duke's C). They were selected to show the reactivity of the early stage of this tumour development. Our study revealed that the tested $R$. caesius extracts expressed no cytotoxic activity. Samples RC2, RC5, and RC6 in a range of concentrations up to $200 \mu \mathrm{g} / \mathrm{mL}$ induced mitochondrial action about 20\% above the HT29 cells control (Figure 2). The SW948 cell line was more sensitive to the activity of the tested samples (RC1-3, RC5) than the HT29 line. The inhibitory effect was concentration-dependent. On the other hand, samples RC4 and RC6 induced succinyl dehydrogenase activity. The tested extracts inhibited, in a concentrationdependent manner, the viability of cells of both HT29 and SW948 lines. The most active was RC5, which, applied at the highest concentration $(250 \mu \mathrm{g} / \mathrm{mL})$, decreased the viability of cells (HT29 and SW948) below 66\% (Figure 3). The butanolic fraction (RC6), which at the highest concentration did not decrease the viability of cells below $87 \%$, was less active. Our tests revealed that $R$. caesius extracts possess reductive activity. All extracts, with the exception of RC1 at a dose of $250 \mu \mathrm{g} / \mathrm{mL}$, almost totally reduced DPPH (Figure 4). RC1 at this concentration reduced only half of the radical. Fractions RC4 and RC5 at the lowest concentrations used expressed strong antioxidative activity. IC $_{50}$ values of the tested samples' activity and their comparison to the Trolox action are presented in Table 2. Antioxidant activity of the selected extracts was also determined by the FRAP method, which is based on the analysis of the $\mathrm{Fe}^{3+}$ ions reduction ability of the tested compounds. The highest $\mathrm{Fe}^{3+}$ ion reduction was shown for the RC4 and RC5 extracts. It was more than 6.5 times higher (at a dose $250 \mu \mathrm{g} / \mathrm{mL}$ ) as compared to the control (Figure 5). This result is comparable to $155 \mu \mathrm{g} / \mathrm{mL}$ of ascorbic acid reductive activity. Similarly to DPPH, the lowest reductive action was shown for the $\mathrm{RCl}$ extract. At the highest concentration applied, its activity was only 2.2 times (activity corresponding to $53 \mu \mathrm{g} / \mathrm{mL}$ of ascorbic acid) stronger than the control.

We showed that the tested extracts (RC1-RC3) and subfractions (RC4-RC6) decreased the viability of cells, acting cytotoxically on tumour cells, and simultaneously expressed strong reductive activity. Our results are in agreement with studies by Durgo et al. [25], showing that red raspberry leaf extract expresses cytotoxic and antioxidative effects in the human colon adenocarcinoma (SW480) cell line. This activity was assigned mainly to polyphenolic compounds present in the plant material. Our results also confirmed results of Dai and coauthors, who revealed that the extracts from blackberry significantly limited HT29 human colon tumour cells growth, and the effect was dependent on the concentration applied. This effect was closely connected with the high content of anthocyanins [22]. Moreover, it was shown that acetone extract of $R$. fairholmianus roots influenced human colon tumour cell morphology and reduced their viability via limitation of the intracellular ATP pool and changes in cells' metabolic activity. As a consequence, depleted ATP quantity decreased the tumour cell proliferation rate and stimulated their death, mainly in the apoptotic pathway [28]. Furthermore, extracts from lyophilized fruits of $R$. occidentalis may modulate host immune system processes by impacting on the function and viability of activated human 


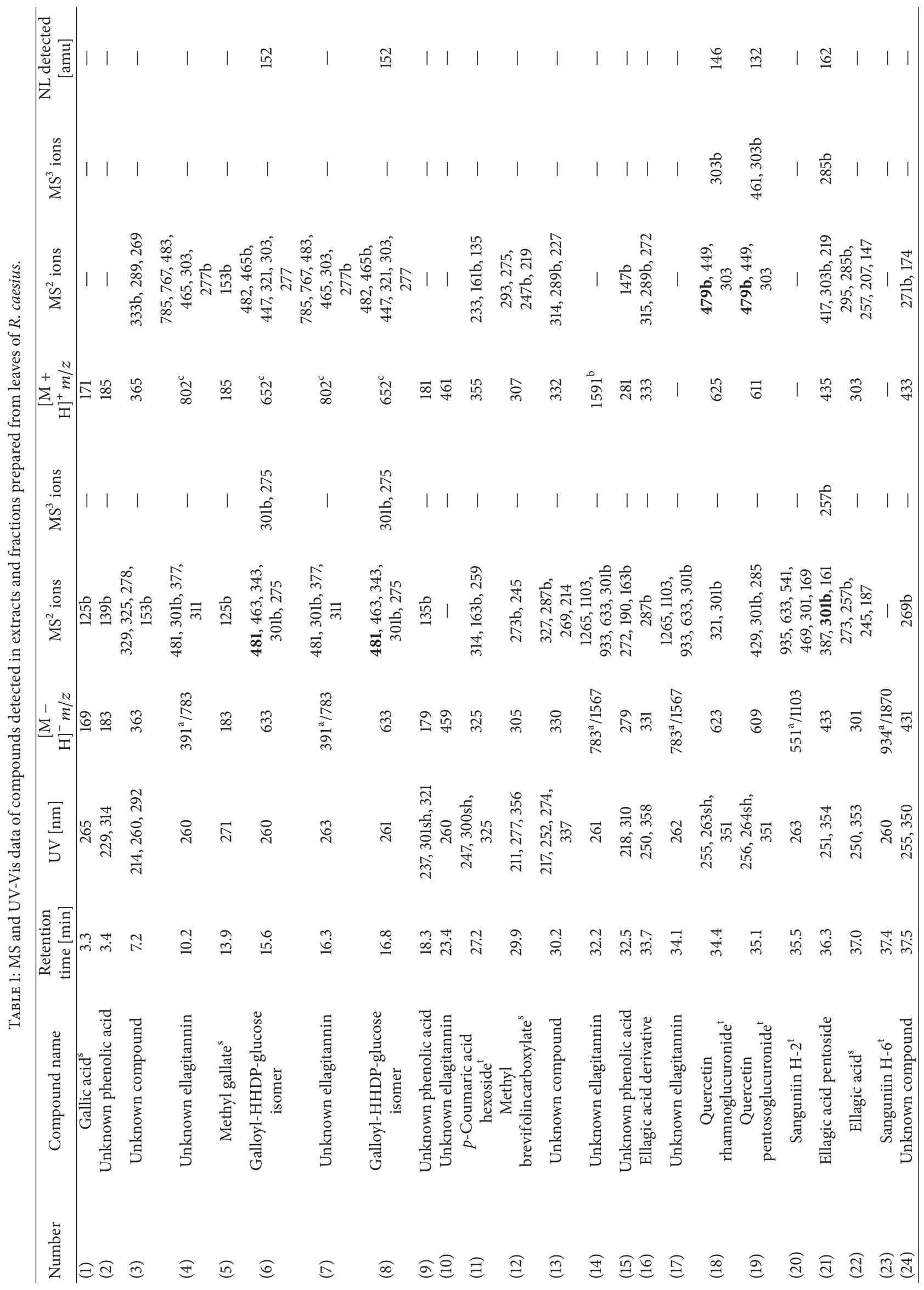




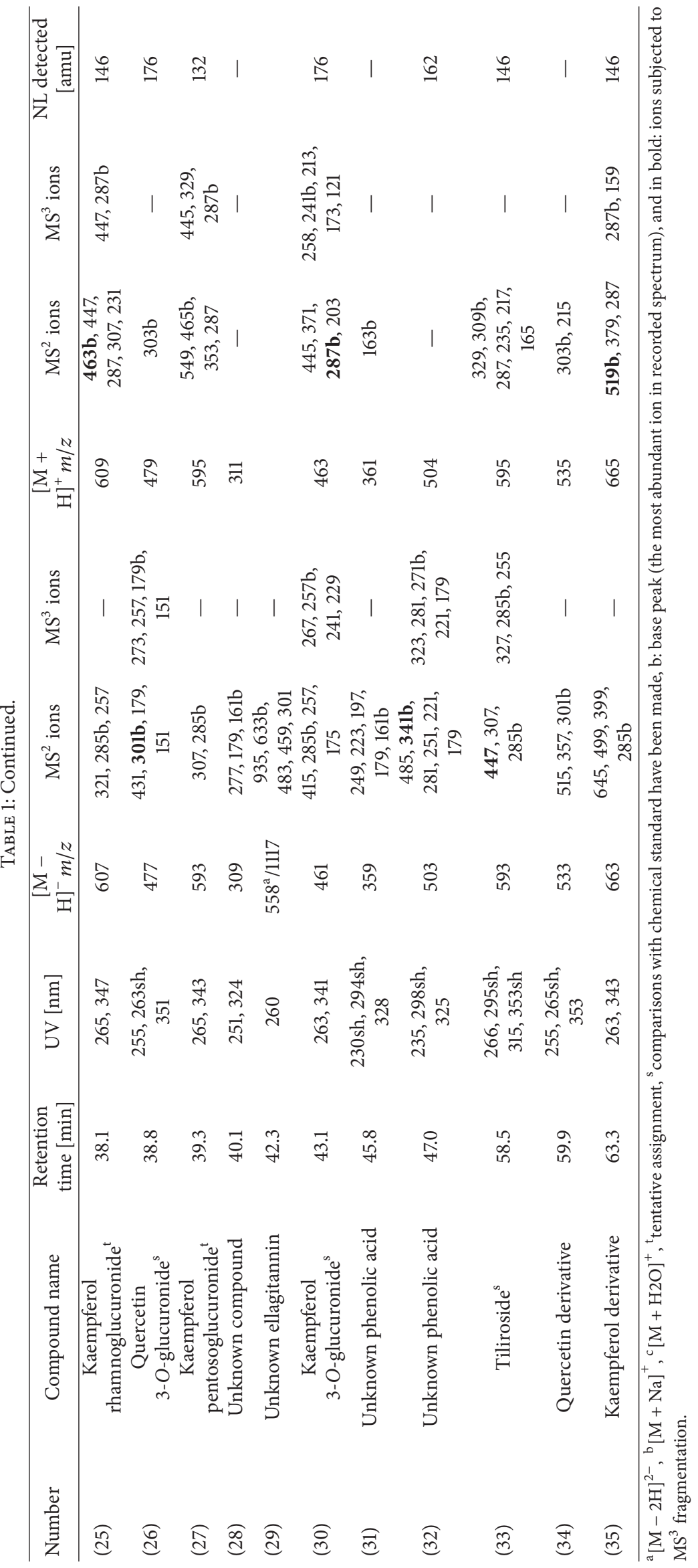




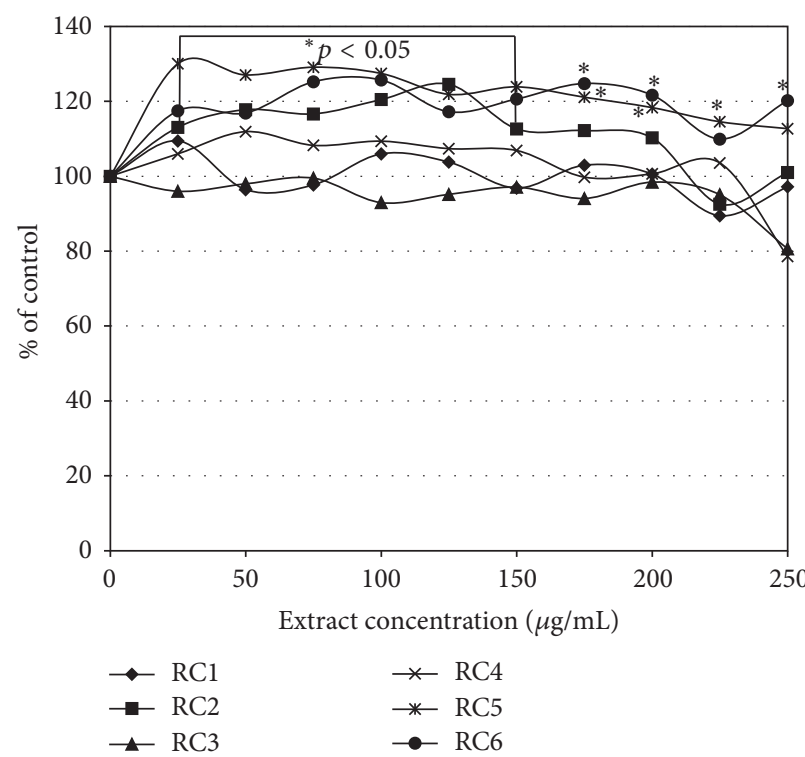

(a)

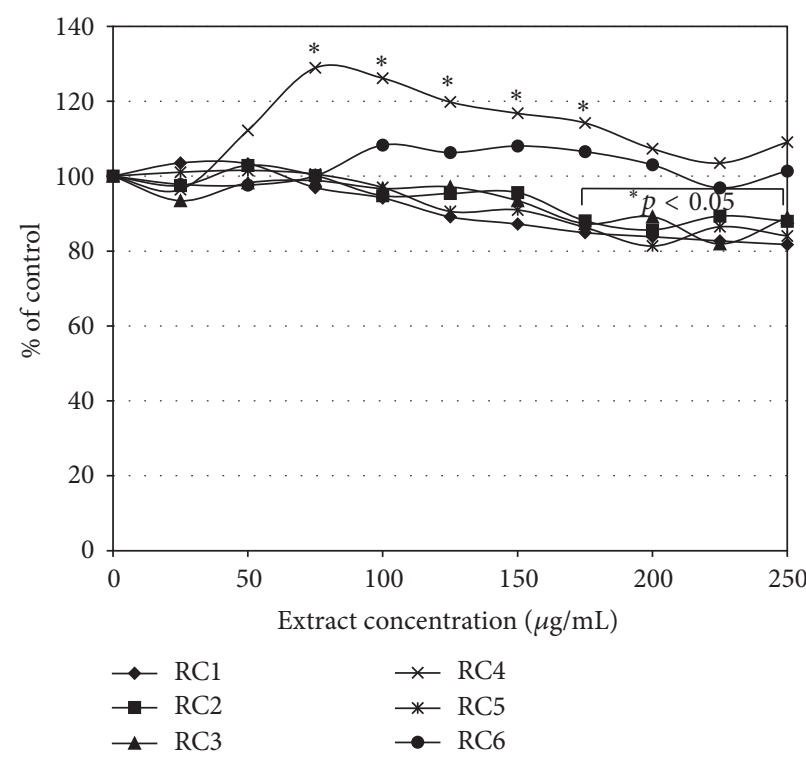

(b)

FIGURE 2: The effect of Rubus caesius extracts influence on HT29 (a) and SW948 (b) metabolic activity. The study was conducted for 24 h. The MTT assay. The results are shown as a percentage of the control, arbitrarily set to $100 \%$.

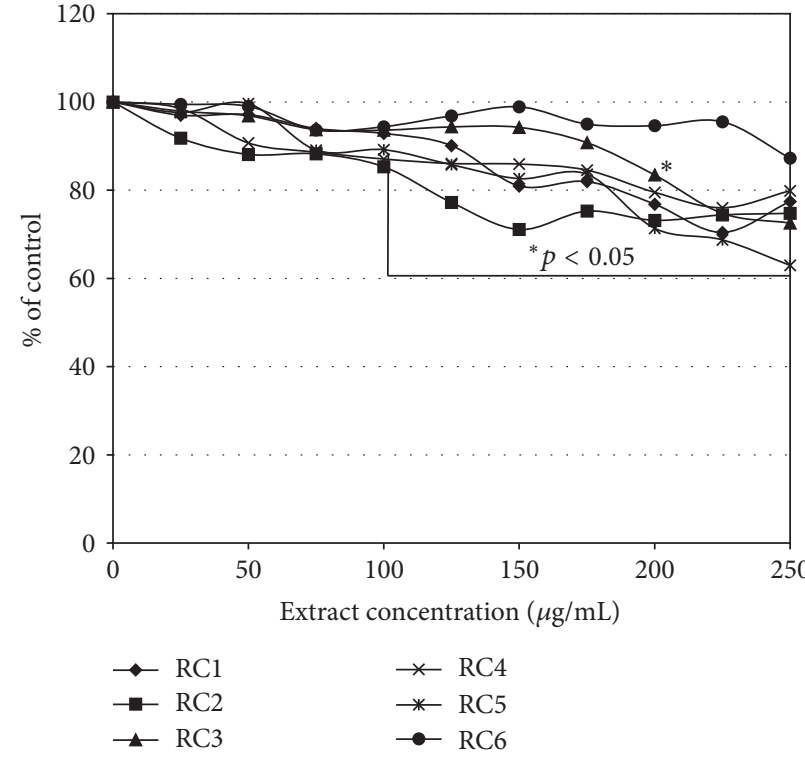

(a)

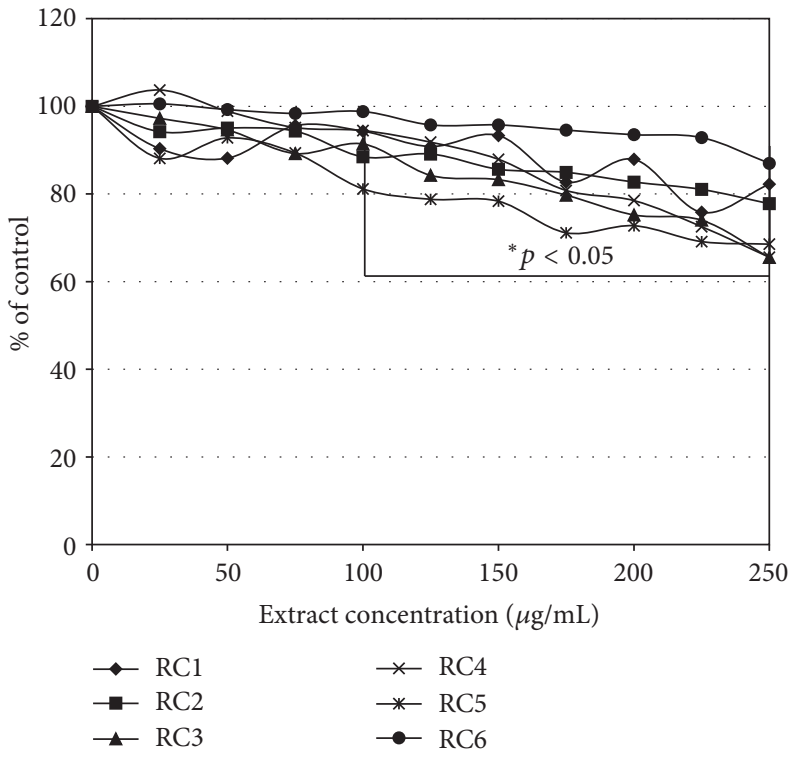

(b)

FIgURE 3: The effect of Rubus caesius extracts influence on HT29 (a) and SW948 (b) cellular membranes stability. The study was conducted for $24 \mathrm{~h}$. The NR uptake assay. The results are shown as a percentage of the control, arbitrarily set to $100 \%$.

CD4+ and CD8+ T lymphocytes [13]. It may indirectly influence tumour cell development and further metastasis. Analyses in this immunological direction have also been expanded with the use of $R$. coreanus extracts loaded in gelatin nanoparticles. They were used as transport vehicles for the plant extracts and resulted in the significant enhancement of T, B, and NK cells' functionality in all areas of their immune activity [14]. Interesting results using cold water extracts of fresh fruits of $R$. caesius were shown by Turker et al. [29], who found a $100 \%$ antitumour efficiency of these extracts on cancer cells. In another study, similar effect was also supported by its antioxidative action with a relatively low $\mathrm{IC}_{50}$ value of $5 \mu \mathrm{g} / \mathrm{mL}$ [19]. Similarly, the shoot extracts of $R$. idaeus were found to be a source of sanguiin H-6 and ellagic acid, which exhibit antioxidative as well as cytotoxic activity [18]. Lee and coauthors additionally revealed that sanguiin H-6 induces morphological changes in tumour cells which are similar to apoptotic features. However, this compound 


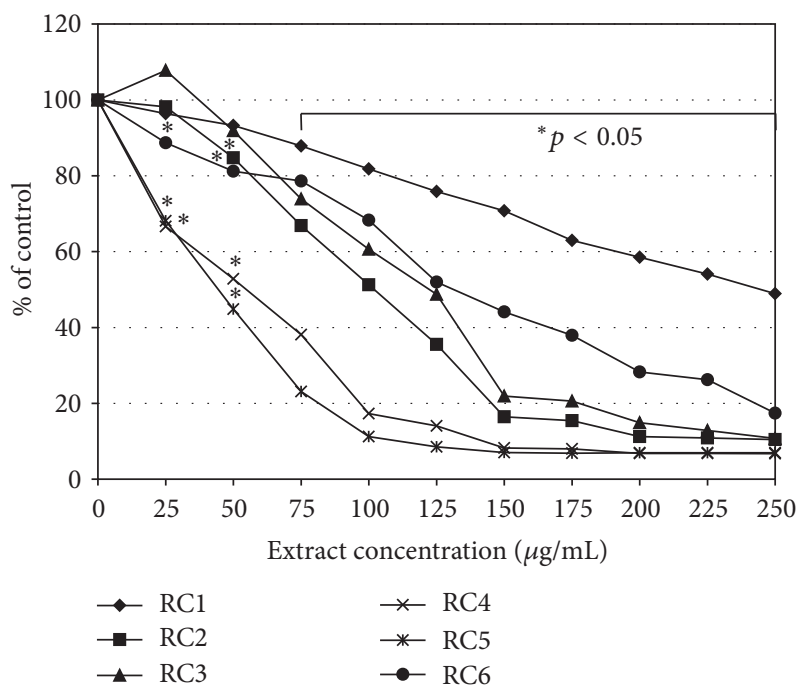

FIgURE 4: The DPPH free radical scavenging activity. The \% of reduced radicals by Rubus caesius extracts is compared to the pure methanol activity set as a nonreducing control ( $0 \%$ reduction).

TABLE 2: DPPH radical reduction assay. $\mathrm{IC}_{50}$ values of extracts action compared to corresponding activity of synthetic vitamin $\mathrm{E}$ derivative (Trolox).

\begin{tabular}{lcc}
\hline Samples & $\begin{array}{c}\text { TColox concentration } \\
\text { activity }(\mu \mathrm{g} / \mathrm{mL})\end{array}$ & $\begin{array}{c}\text { of extract } \\
(\mu \mathrm{g} / \mathrm{mL}) \text { which } \\
\text { corresponds to } \mathrm{IC}_{50} \text { of } \\
\text { extract activity }\end{array}$ \\
\hline RC1 & 240.9 & 20.5 \\
RC2 & 101.8 & 26.8 \\
RC3 & 123.5 & 32.7 \\
RC4 & 54.8 & 23.0 \\
RC5 & 44.5 & 21.3 \\
RC6 & 131.3 & 23.0 \\
\hline
\end{tabular}

does not affect the cancer cell cycle. In general, the molecular pathway of sanguiin H-6 activity is mediated by MAPK p38 and BID cleavage with the participation of caspase-8 [20]. Kim and coworkers have shown that the aqueous extract of the incompletely ripened fruit of $R$. coreanum inhibits cell proliferation and stimulates apoptosis in HT29 cells and that this may be mediated by its ability to activate the caspase- 3 pathway [30]. In other study, Bowen-Forbes and coworkers showed that fruit extracts obtained from some Rubus species also exhibited great potential to inhibit colon, breast, lung, and gastric cancer cell growth. The authors speculate that the anticancer effect may partially depend on inhibitory action on cyclooxygenase-2 (COX-2) functionality. Moreover, due to high anthocyanin content, it may also strongly influence the oxidative condition in the tumour cell microenvironment [23].

Besides the general activity of Rubus extracts on tumour cells, it was shown that the range of such action is based on the horticultural parameters of the plant material. Production

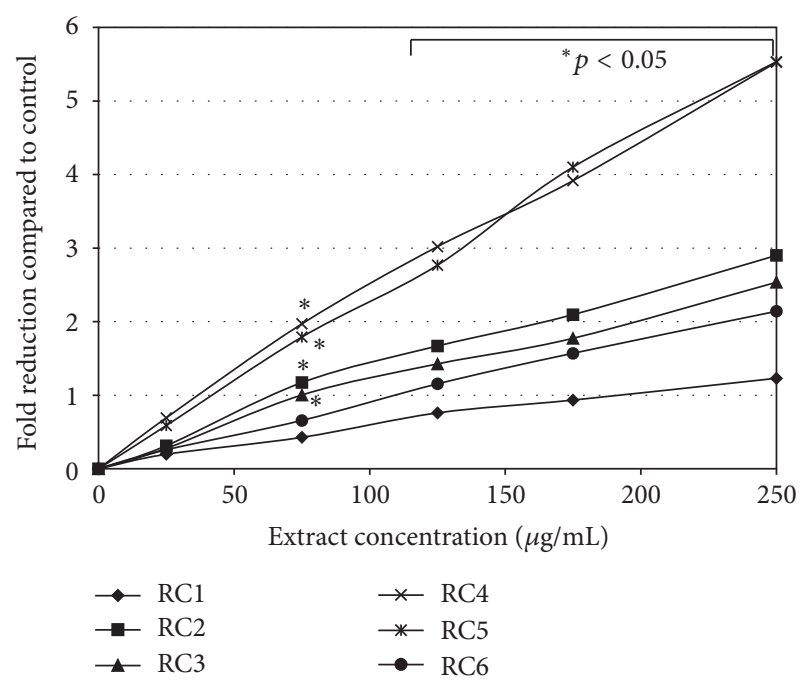

FIGURE 5: Ferric-reducing activity assay. The $\%$ of reduced ferric ions by Rubus caesius extracts is compared to the untreated control $(0 \%$ reduction).

factors, both genetic and environmental, determine the usefulness of plants as a material for specific destiny, for example, chemoprevention. Therefore, the degree of inhibition of human colon tumour cell proliferation depends not only on general active phytoconstituents presence, but also on their specific composition which is dependent on cultivar, production site, or stage of maturity [21].

Generally, plant extracts have many biological activities directly aimed at cell morphology and proliferation or indirectly by possessing reductive feature which influence inflammatory state modulating immune system reactivity. In our study $R$. caesius leaf extract revealed tumour cell growth limiting activity, on both the morphology and metabolism levels. Moreover, its antioxidative activity may be connected with colon origin tumour cells growth reduction.

\section{Competing Interests}

The authors declare that there is no conflict of interests regarding the publication of this paper.

\section{References}

[1] A. M. Rejewska, A. Sikora, M. Tomczykowa, and M. Tomczyk, "Rubus caesius," Pharmacognosy Communications, vol. 3, no. 1, pp. 55-57, 2013.

[2] M. Tomczyk, M. Pleszczyńska, A. Wiater, and S. Granica, "In vitro anticariogenic effects of Drymocallis rupestris extracts and their quality evaluation by HPLC-DAD-MS ${ }^{3}$ analysis," Molecules, vol. 18, no. 8, pp. 9117-9131, 2013.

[3] T. Mosmann, "Rapid colorimetric assay for cellular growth and survival: application to proliferation and cytotoxicity assays," Journal of Immunological Methods, vol. 65, no. 1-2, pp. 55-63, 1983.

[4] R. Paduch, A. Woźniak, P. Niedziela, and R. Rejdak, "Assessment of eyebright (Euphrasia officinalis L.) extract activity in 
relation to human corneal cells using in vitro tests," Balkan Medical Journal, vol. 31, no. 1, pp. 29-36, 2014.

[5] R. Paduch and A. Woźniak, "The effect of Lamium album extract on cultivated human corneal epithelial cells (10.014 pRSV-T)," Journal of Ophthalmic and Vision Research, vol. 10, no. 3, pp. 229-237, 2015.

[6] A. V. Patel, J. Rojas-Vera, and C. G. Dacke, “Therapeutic constituents and actions of Rubus species," Current Medicinal Chemistry, vol. 11, no. 11, pp. 1501-1512, 2004.

[7] G. O. Rocabado, L. M. Bedoya, M. J. Abad, and P. Bermejo, "Rubus-a review of its phytochemical and pharmacological profile," Natural Product Communications, vol. 3, no. 3, pp. 423436, 2008.

[8] L. Holst, S. Haavik, and H. Nordeng, "Raspberry leaf-should it be recommended to pregnant women?" Complementary Therapies in Clinical Practice, vol. 15, no. 4, pp. 204-208, 2009.

[9] S. C. Gouveia-Figueira and P. C. Castilho, "Phenolic screening by HPLC-DAD-ESI/MS $\mathrm{n}_{\mathrm{n}}$ and antioxidant capacity of leaves, flowers and berries of Rubus grandifolius Lowe," Industrial Crops and Products, vol. 73, pp. 28-40, 2015.

[10] J. Li, L.-F. Du, Y. He et al., "Chemical constituents and biological activities of plants from the genus Rubus," Chemistry \& Biodiversity, vol. 12, no. 12, pp. 1809-1847, 2015.

[11] J. Gudej and M. Tomczyk, "Determination of flavonoids, tannins and ellagic acid in leaves from RubusL. species," Archives of pharmacal research, vol. 27, no. 11, pp. 1114-1119, 2004.

[12] D. Dudzinska, K. Bednarska, M. Boncler, B. Luzak, and C. Watala, "The influence of Rubus idaeus and Rubus caesius leaf extracts on platelet aggregation in whole blood. Cross-talk of platelets and neutrophils," Platelets, vol. 27, no. 5, pp. 433-439, 2016.

[13] T. A. Mace, S. A. King, Z. Ameen et al., "Bioactive compounds or metabolites from black raspberries modulate T lymphocyte proliferation, myeloid cell differentiation and Jak/STAT signaling," Cancer Immunology and Immunotherapy, vol. 63, no. 9, pp. 889-900, 2014.

[14] Y. C. Seo, W. Y. Choi, C. G. Lee et al., "Enhanced immunomodulatory activity of gelatin-encapsulated Rubus coreanus Miquel nanoparticles," International Journal of Molecular Sciences, vol. 12, no. 12, pp. 9031-9056, 2011.

[15] B. P. George, T. Parimelazhagan, Y. T. Kumar, and T. Sajeesh, "Antitumor and wound healing properties of Rubus ellipticus Smith," Journal of Acupuncture and Meridian Studies, vol. 8, no. 3, pp. 134-141, 2015.

[16] T.-T. Zhang, C.-L. Lu, J.-G. Jiang, M. Wang, D.-M. Wang, and W. Zhu, "Bioactivities and extraction optimization of crude polysaccharides from the fruits and leaves of Rubus chingii Hu," Carbohydrate Polymers, vol. 130, pp. 307-315, 2015.

[17] E. M. Brown, C. I. R. Gill, G. J. McDougall, and D. Stewart, "Mechanisms underlying the anti-proliferative effects of berry components in in vitro models of colon cancer," Current Pharmaceutical Biotechnology, vol. 13, no. 1, pp. 200-209, 2012.

[18] M. Krauze-Baranowska, D. Głód, M. Kula et al., "Chemical composition and biological activity of Rubus idaeus shootsa traditional herbal remedy of Eastern Europe," BMC Complementary and Alternative Medicine, vol. 14, article no. 480, 12 pages, 2014.

[19] F. Conforti, M. Marrelli, C. Carmela et al., "Bioactive phytonutrients (omega fatty acids, tocopherols, polyphenols), in vitro inhibition of nitric oxide production and free radical scavenging activity of non-cultivated Mediterranean vegetables," Food Chemistry, vol. 129, no. 4, pp. 1413-1419, 2011.
[20] D. Lee, H. Ko, Y.-J. Kim et al., "Inhibition of A2780 human ovarian carcinoma cell proliferation by a Rubuscomponent, sanguiin H-6," Journal of Agricultural and Food Chemistry, vol. 64, no. 4, pp. 801-805, 2016.

[21] J. L. Johnson, J. A. Bomser, J. C. Scheerens, and M. M. Giusti, "Effect of black raspberry (Rubus occidentalis L.) extract variation conditioned by cultivar, production site, and fruit maturity stage on colon cancer cell proliferation," Journal of Agricultural and Food Chemistry, vol. 59, no. 5, pp. 1638-1645, 2011.

[22] J. Dai, J. D. Patel, and R. J. Mumper, "Characterization of blackberry extract and its antiproliferative and anti-inflammatory properties," Journal of Medicinal Food, vol. 10, no. 2, pp. 258265, 2007.

[23] C. S. Bowen-Forbes, Y. Zhang, and M. G. Nair, "Anthocyanin content, antioxidant, anti-inflammatory and anticancer properties of blackberry and raspberry fruits," Journal of Food Composition and Analysis, vol. 23, no. 6, pp. 554-560, 2010.

[24] P. Rajendran, E. Ho, D. E. Williams, and R. H. Dashwood, "Dietary phytochemicals, HDAC inhibition, and DNA damage/repair defects in cancer cells," Clinical Epigenetics, vol. 3, no. 1, article 4, 2011.

[25] K. Durgo, A. Belščak-Cvitanović, A. Stančić, J. Franekić, and D. Komes, "The bioactive potential of red raspberry (Rubus idaeus L.) leaves in exhibiting cytotoxic and cytoprotective activity on human laryngeal carcinoma and colon adenocarcinoma," Journal of Medicinal Food, vol. 15, no. 3, pp. 258-268, 2012.

[26] D. Komes, A. Belščak-Cvitanović, I. Ljubičić et al., "Formulating blackberry leaf mixtures for preparation of infusions with plant derived sources of sweeteners," Food Chemistry, vol. 151, pp. 385-393, 2014.

[27] J.-S. Shin, E.-J. Cho, H.-E. Choi et al., "Anti-inflammatory effect of a standardized triterpenoid-rich fraction isolated from Rubus coreanus on dextran sodium sulfate-induced acute colitis in mice and LPS-induced macrophages," Journal of Ethnopharmacology, vol. 158, pp. 291-300, 2014.

[28] B. P. A. George, I. M. Tynga, and H. Abrahamse, "In vitro antiproliferative effect of the acetone extract of Rubus fairholmianus gard. Root on human colorectal cancer cells," BioMed Research International, vol. 2015, Article ID 165037, 8 pages, 2015.

[29] A. U. Turker, A. B. Yildirim, and F. P. Karakas, "Antibacterial and antitumor activities of some wild fruits grown in Turkey," Biotechnology and Biotechnological Equipment, vol. 26, no. 1, pp. 2765-2772, 2012.

[30] E. J. Kim, Y.-J. Lee, H.-K. Shin, and J. H. Y. Park, "Induction of apoptosis by the aqueous extract of Rubus coreanum in HT-29 human colon cancer cells," Nutrition, vol. 21, no. 11-12, pp. 11411148, 2005. 


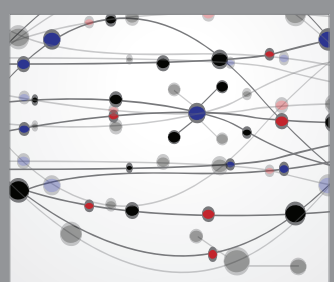

The Scientific World Journal
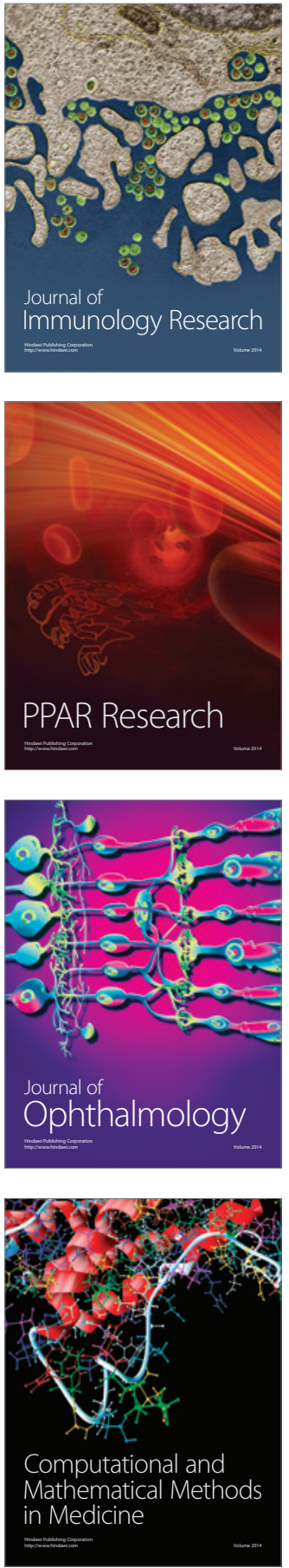

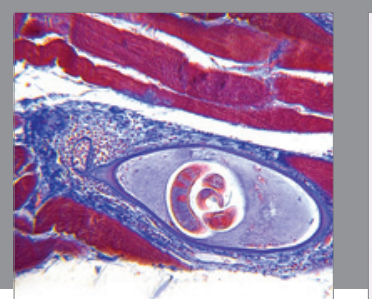

Gastroenterology Research and Practice

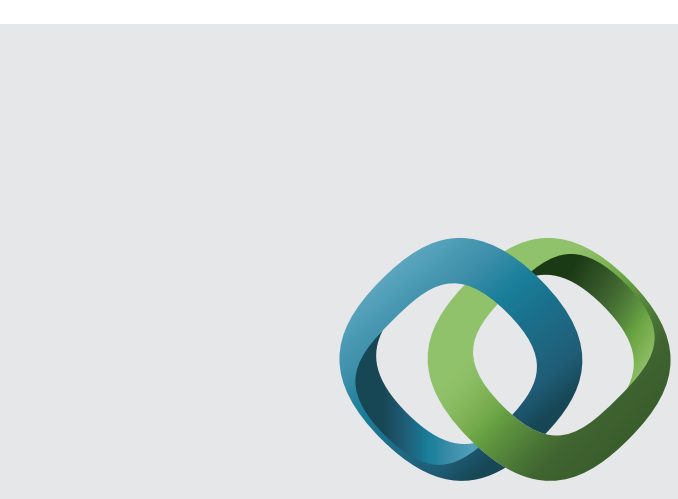

\section{Hindawi}

Submit your manuscripts at

http://www.hindawi.com
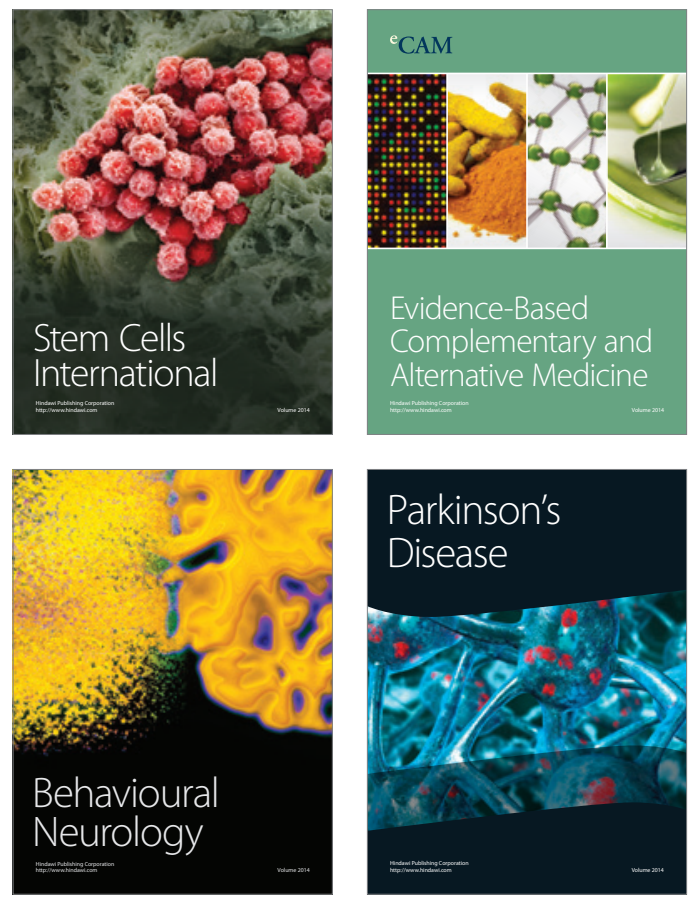
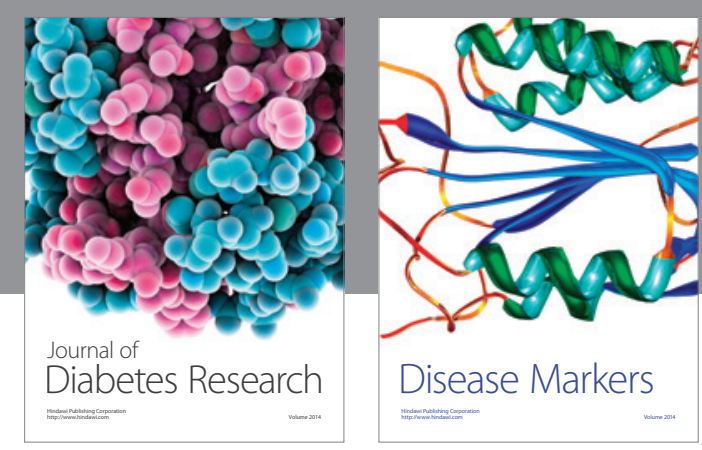

Disease Markers
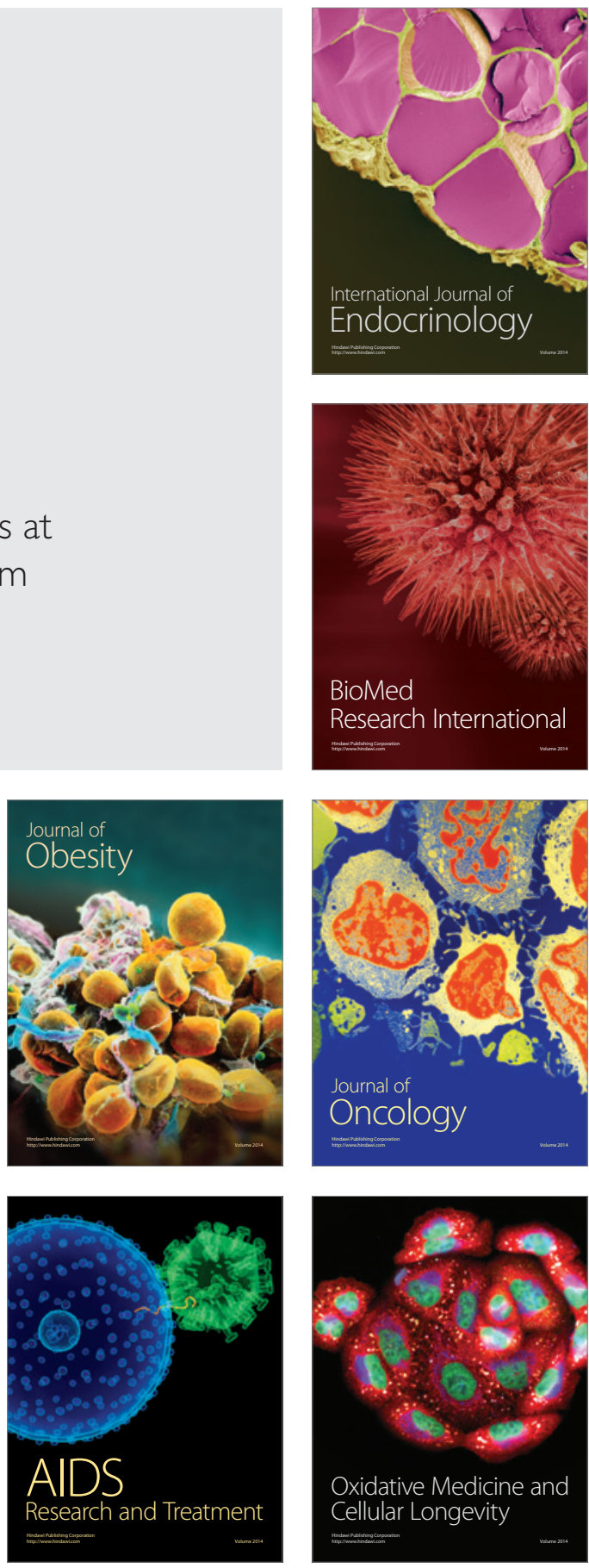